\title{
Information Technology and $\mu$ Controller Applications to Support Experiential Learning of Students
}

\author{
K. Kalovrektis \\ Dept. of Informatics \\ University of \\ Thessaly \\ Lamia, Greece
}

\author{
M. Papoutsidakis \\ Dept. of Automation \\ Engineering \\ PUAS, Athens, \\ Greece
}

\author{
C. Drosos \\ Dept. of Automation \\ Engineering \\ PUAS, Athens, \\ Greece
}

\author{
G. Stamoulis \\ Dept. of Informatics \\ University of \\ Thessaly \\ Lamia, Greece
}

\begin{abstract}
The use of Information and Communication Technology has recently be adopted by the Greek community in every process of education. Most of the times, these technologies are applied only for information research over the internet, multimedia application and simulation. Considering that a student realizes and is attracted more from things that can manipulate according to the educational model, the need for an advanced interface that will use real physical parameters like temperature and speed, is generated. Students will then be able to develop skills and behaviors via the process of real data and circumstances management. In this study the development and implementation of such an interface environment is presented that has as main goal the understanding of the students about the thermic load of a town and the cement influence in the temperature increase of the same town.
\end{abstract}

\section{Keywords}

Experiential learning, environmental education, computer interface

\section{INTRODUCTION}

The environmental education is a main factor in the educational process with a strong orientation in the biophysical environment and civilization research, aiming in the trends development of the idea that humans have about the environment that they live in. The experiential learning acts in a model frame that learning and skills development of the students are achieved via social events participation, team work etc. The last years Greek Government introduced a law frame that all schools reformed their curriculum and included this kind of technologies in primary and secondary levels of education, establishing the environmental courses as main part of the overall educational process.

Over the years, the appearance of pre-programmed lectures, seminars and workshops, was a challenge for teachers and tutors to interfere is some form of environmental education. Although the Greek Ministry of Education encourages teachers to include information technology systems to support the environmental education, the result of such implementation still leave space for improvement. A unified platform that would link technology with environmental education is not provided to teachers and therefore real data acquisition and measurements of physical parameters cannot be collected. Instead, all learning process is executed with statistical data and the personal experience of each tutor. The work in this paper actually tries to fulfil this gap and introduce an innovative idea of the above problem solution. The proposed real time acquisition interface, which will be based on a modern microcontroller device, will also provide the users (students) the necessary support to understand the experiential learning in a better way rather than a simulation program for instance would do. This interface was designed and implemented in a team of students for the needs of environmental education course and was used for experimentation in the city of Livadia, Sterea Ellada, Greece.

\section{EXPERIENTIAL LEARNING MODEL}

According to this model, a student is straight involved in the real world of his research or study. This model stands on the contrary of any traditional educational method and didactic approaches. This means that the student stops being a simple observer of messages or situations and becomes a true participant in the whole process of learning. The basic aim is the fact that students increase their learning level and develops a deeper understanding of the meanings and the phenomena that they investigate just because they are now able to witness all physical parameters changes in reality.

In particular the implementation of experiential learning in the environmental education, provide the users the ability to live in the subject they are investigating as well as to increase their principles, emotions and behavior factors of the environment they live in and at the same time develop their research spirits in order to solve and deal with scientific approaches. As a result they gain from team work, acquire technological skills and build a strong self-esteem.

At the end of the day this model is considered to be especially appropriate in order to help student to build their intelligence, critical thinking and their personality overall.

\section{ELECTRONIC EQUIPMENT}

The description of the system is divided in the following two sub-sections, each one of them represents a different method based on separate electronic equipment, in an attempt to build more than one solution for the task. As a result, the student team had two different modern technological platforms to experiment with and would be able to gather real environmental data in a pre-design route on the town streets.

\subsection{The $1^{\text {st }}$ System's Description}

In order to build a system that could collect and monitor environmental data while at the same time being user friendly for the students, two platforms were designed and afterwards implemented. Both of them were selected based on criteria of low cost, easy programming and handling since students who would use them do not have yet establish a higher education level referring to such devices. They would use these devices to measure and monitor ground temperature, environmental temperature and humidity.

The $1^{\text {st }}$ platform of them consists of: 
- A laptop computer

- Data acquisition interface card, NI 6008 with USB connection

- Humidity sensor HU1012NA

- Temperature sensor SMT160

- Labview Interface design to collect and monitor all measurements and data.

At this point, it must be stated that although the Data Acquisition card, NI6008 comes with its own Windows compatible software as shown in figure ZZZZZZ, it was decided to monitor and interact with the system with Labview program for better understanding and easier use. In figure 1 the laptop with Labview loaded can be seen:

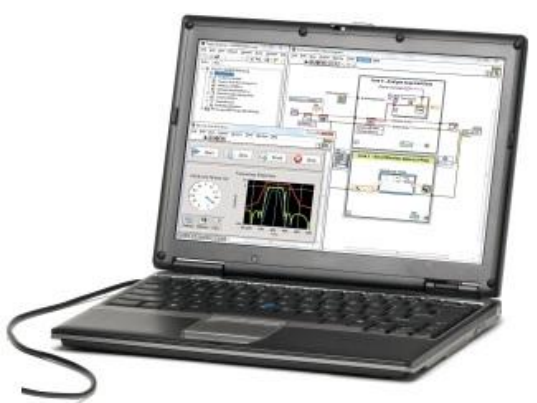

Fig 1.: LabVIEW program on laptop screen

The specifications of the data acquisition card are provided in the below figure:

\section{A.4. NI USB-6008}

- NI USB-6008 is a simple and low-cost multifunction I/O device from National Instruments.

- The device has the following specifications:

8 analog inputs (12-bit, $10 \mathrm{kS} / \mathrm{s}$ )

$>2$ analog outputs (12-bit, $150 \mathrm{~S} / \mathrm{s}$ )

$>12$ digital $\mathrm{V} / \mathrm{O}$

- USB connection, No extra power-supply neeeded

> Compatible with LabVIEW, LabWindows/CVI, and Measurement Studio for Visual Studio NET

$>$ NI-DAQmx driver software

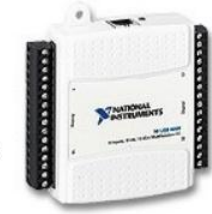

- The NI USB-6008 is well suited for education purposes due to its small size and easy USB connection.

\section{Fig 2.: NI 6008 specs table}

The NI 6008 board has an interactive control panel that cooperates with Windows, as shown in figure 3 , while the interface between the user and the system is shown in figure 4.

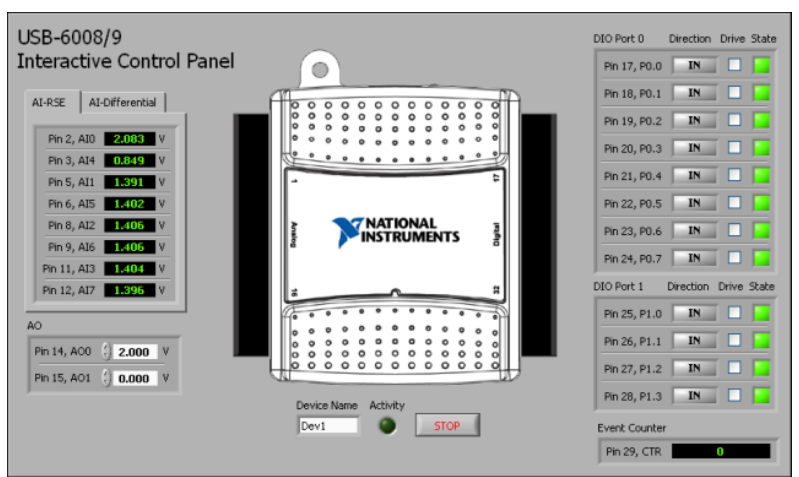

Fig 3.: NI 6008 interactive control panel

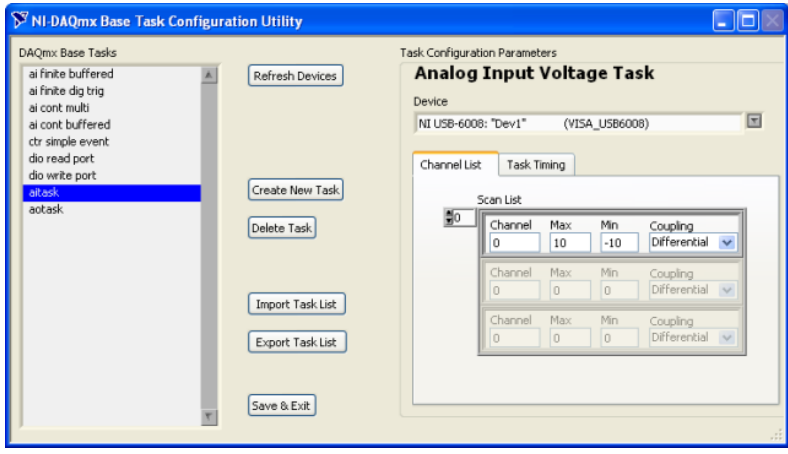

Fig 4.: NI 6008 Windows interface

The temperature sensor and the humidity sensor are illustrated in figures 5 and 6 respectively.

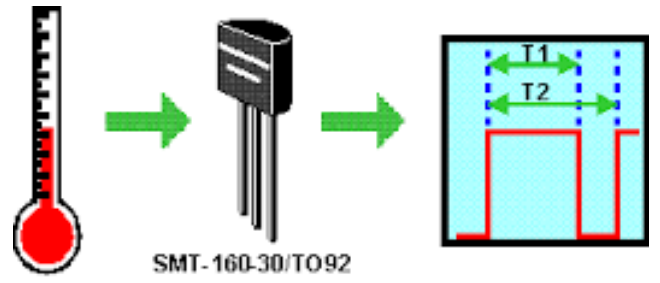

Fig 5.: temperature sensor

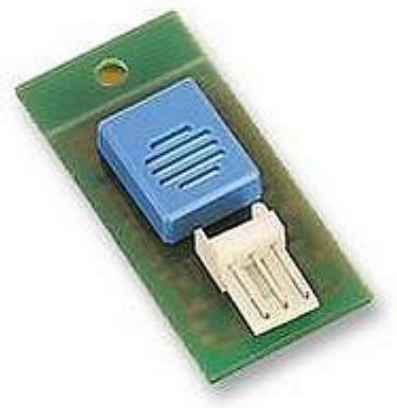

Fig 6.: humidity sensor

The block diagram of the system is provided below:

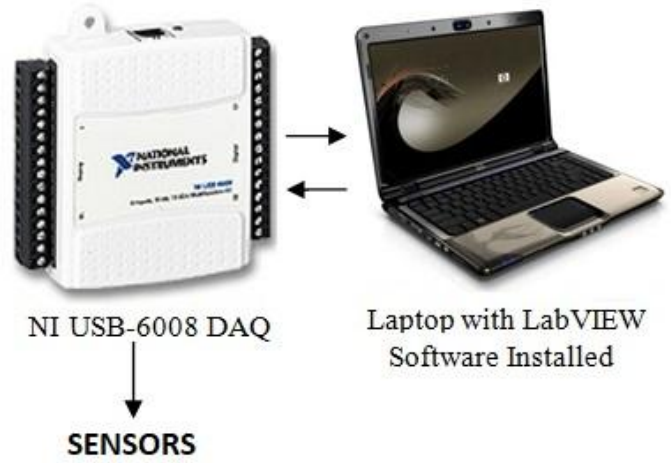

Fig 7.: block diagram of the system

This project was an excellent opportunity for students to work as teams or groups and connect all equipment in order to build the system, as shounw in the following figure. 


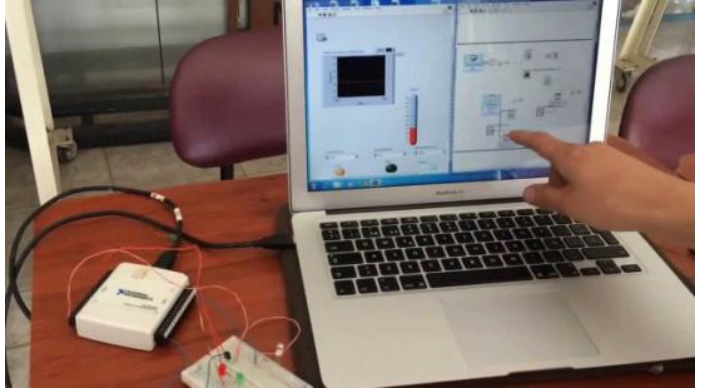

Fig 8.: Laboratory experimentation

Once the equipment was connected and the system started to operate the LabVIEW main command window was designed for the user to monitor all collected data.

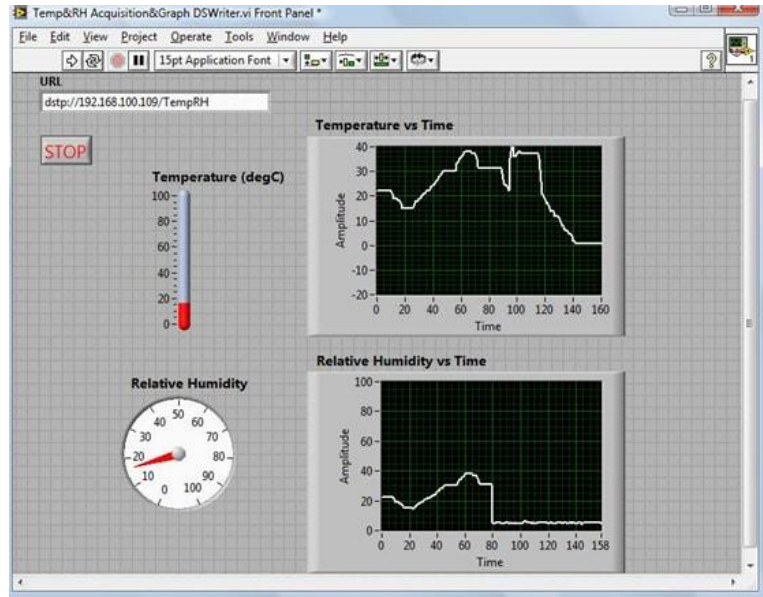

Fig 9.: LabVIEW interface

\subsection{The $2^{\text {nd }}$ System's Description}

The second system that was used for the task, as an alternative solution, was based on Raspberry PI Model B technology, which is a computer on a board solution, it is an integrated microcontroller that can be easily programmed and connected with a PC via Ethernet cable or via WiFi protocol. A brief presentation is given in figure 10 .

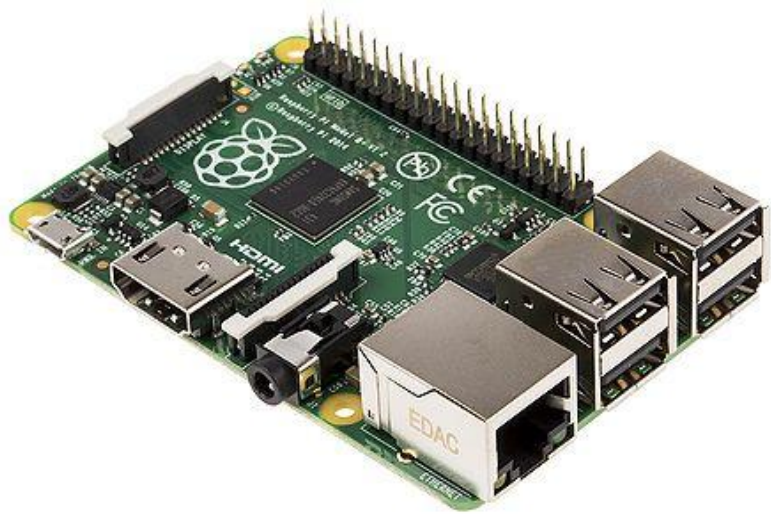

Fig 10.: Laboratory experimentation
This device was selected upon its characteristics of low cost, multiple connectivity with a PC and its capability to interact with the same temperature and humidity sensors or the $1^{\text {st }}$ system discussed earlier. The microcontroller's placement in the system is shown below

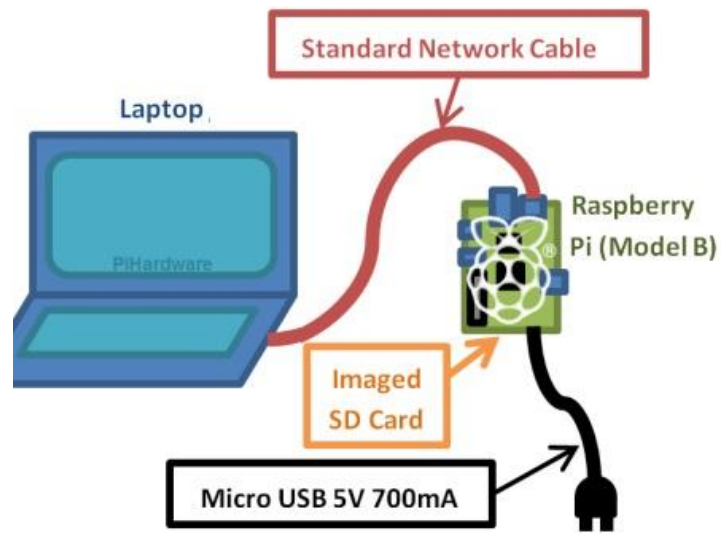

Fig 11.: $2^{\text {nd }}$ system's block diagram

This second choice of gear, although at the time of presenting this paper was not concluded in terms of data collection, provided the students with the ability of distance control between the sensors and the users as long as there is $\mathrm{WiFi}$ coverage in the area. This is another challenge that the students should follow in the short future.

\section{METHODOLOGY}

For the experimentation and the real time data collection in the city, the students were split in two main teams, providing to all the same opportunity of participating in the experiential learning process. The first team called "virtual team" worked inside the school's laboratory based on simulated data in LabView which were collected from virtual sensors. The second team called "experimental team" was responsible to collect measurements in the real world i.e. inside the city, were the above described systems represented their tools.

Both teams mapped a 13 points plan, by using Google Maps, inside the city that the thermal load should be acquired. The virtual team according to its experience and knowledge of the geographical data of the city, illustrated data about temperature and humidity on the city map by using the simulation software (figure 9). The second "experimental team" by using the data acquisition equipment of the previous chapter, undertook real measurements in the pre-decided points. These were selected with multiple criteria like, the city suburbs, in the city center were road traffic increases, inside public parks and beside the river that flows inside the city. By using their experimental devices they gathered data from all these city points and saved them in separate files in their portable PC. This route is illustrated in figure 12 . 


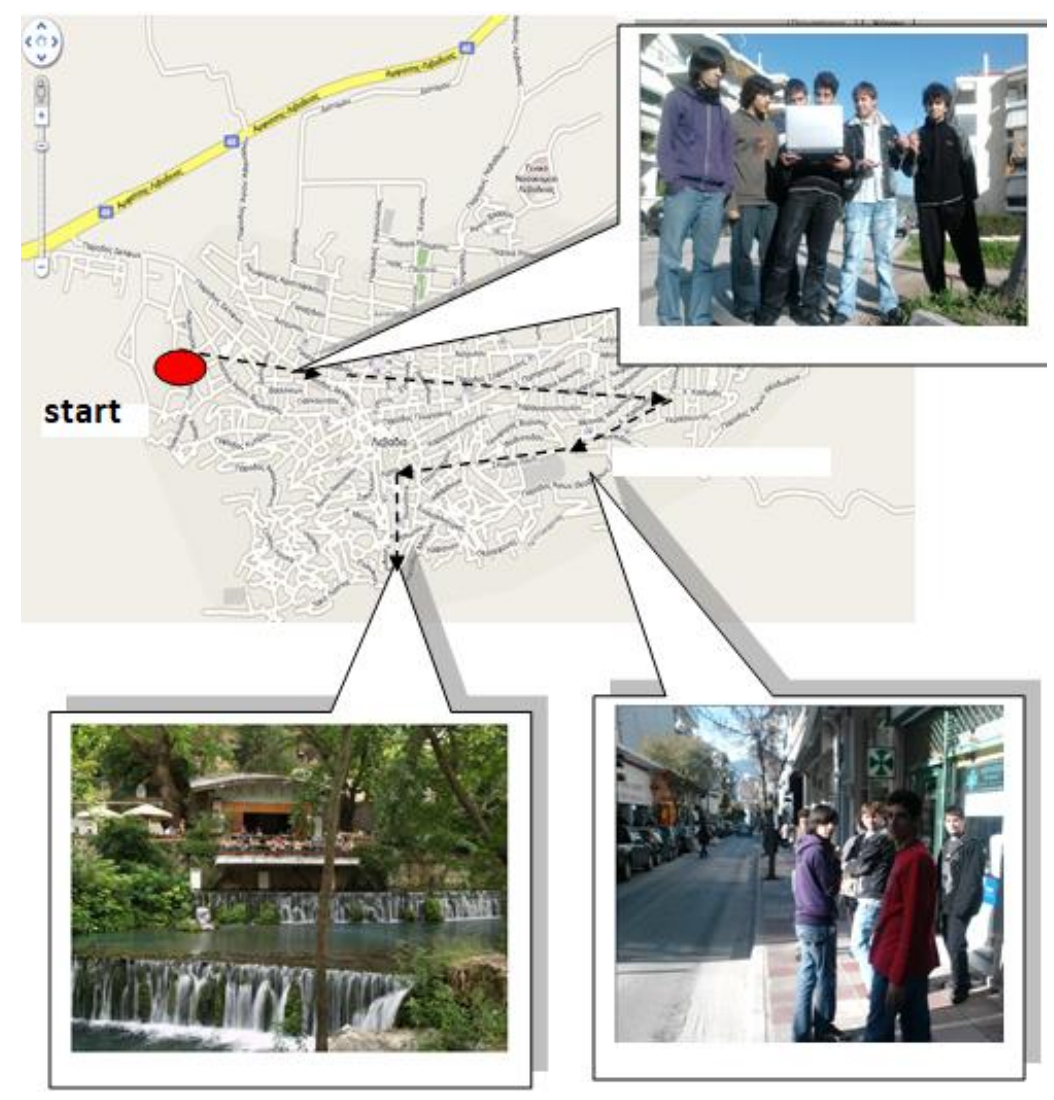

Fig 12.: Students collecting data inside the city of Levadia

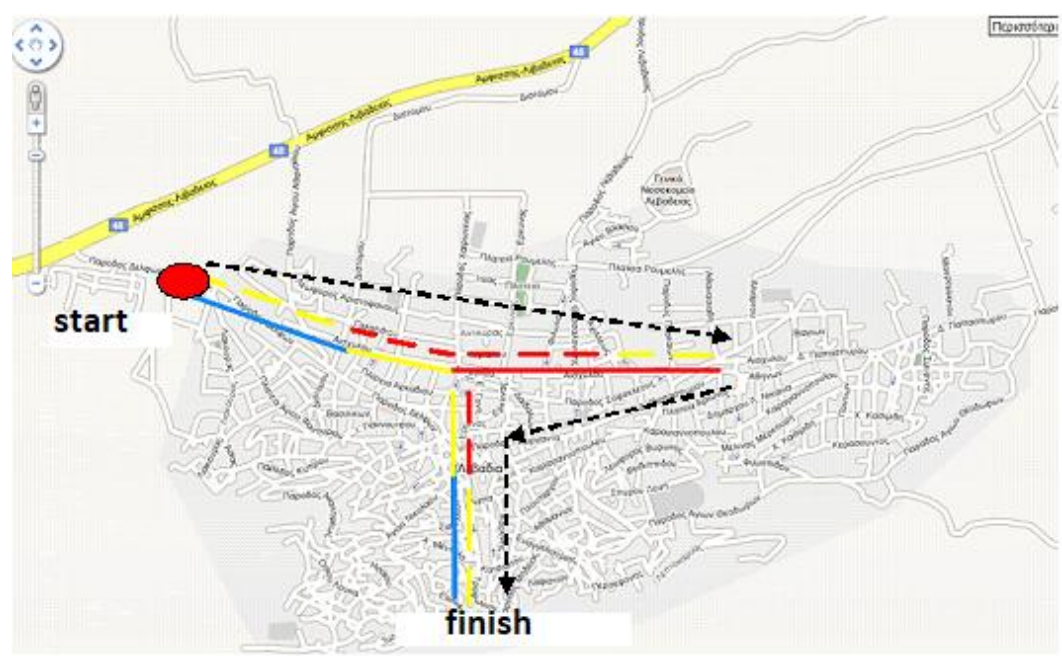

Fig 13.: Thermal load in the city

\section{RESULTS AND DISCUSSION}

In the above figure 13, one can see the thermal load in the city as it was measured by students. The red represents high thermal load, yellow is moderate load whereas blue stands for low level thermal load. The part of the city in red is in the center of it, with narrow streets and a lot of traffic. On the contrary, the yellow and moreover the blue thermal load was captured in the suburbs of the city and especially close to the city river. At this stage it needs to be declared that the map of figure 13 represents the monitoring of the "experimental team" data acquisition process, which is far different from the monitoring that the "virtual team" produced in the laboratory via simulation. The reason for this relies on the fact that the use of virtual environmental parameters can lead students to wrong estimations and force them to decide and therefore input wrong data in the simulation program. This is why the use of interface programs in the real world is more reliable and increases the right learning of the students rather than the simulation process. In addition, the critical thinking of students is further developed referring to the overall environmental factors and parameters. At the end of this case study, students-members of both teams filled in respective questionnaires about this experimental process in order to extract useful conclusions.

In figure 14 , there is a plot that indicates the satisfaction level of the experimental team versus the virtual team. It is more than obvious that when students handle real equipment, they 
understand better the learning process and they leave questions for further research and investigations.

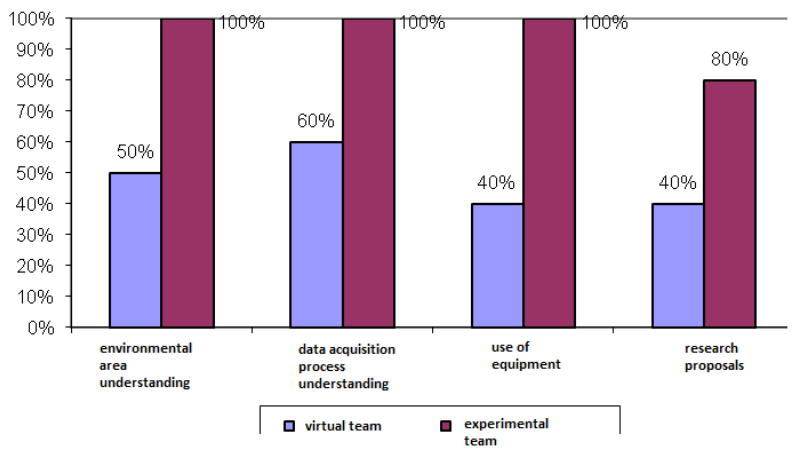

Fig 14.: Questionnaire's outcomes

The learning influence and the challenge which was undertaken by the students, was significantly higher for the members of the experimental team, which is another outcome of the hypothesis that when students manage multimedia and hardware equipment for experimentation, they perform far better. This is shown in the next figure.

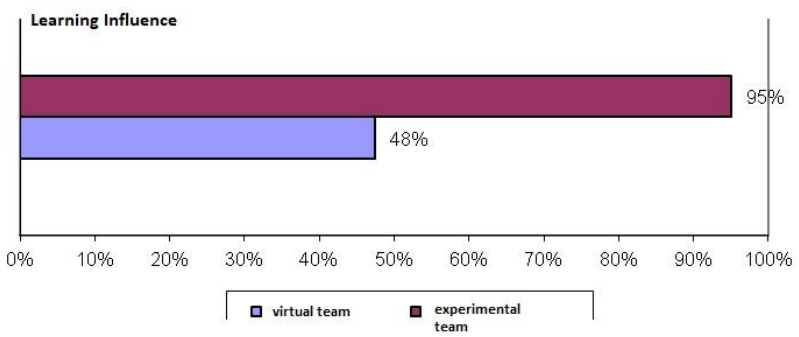

Fig 15.: Learning Influence plot

\section{CONCLUSIONS}

If somebody could witness the students' attempts and experimentations, he could write down a list of benefits and advantages that this method recorded in the learning process.

1. The use of software of data acquisition of real parameters and the team work via the experiential learning model, develops the research spirit of any student throughout scientific approaches with the use of real data and measurements.

2. The use of real time data collection interface supports and amplifies the experiential learning in a greater deal than the virtual software and simulations in a way that, students develop skills of real data management and increase their awareness of physical parameters.

3. The use of personal computer as a scientific tool for the data acquisition and monitoring process, provides a helpful tool to students for winding their perception of what a computer can do more than internet research and virtual reality.

4. The real data collection interface provides the opportunity to a student to discover unknown knowledge through practical applications, spot the necessary tools for that and propose the methodology of his own research.

Speaking of research and what is to follow this case study, the still undergoing experiment with the $2^{\text {nd }}$ system presented earlier will be implemented and tested in the short future. This should be a great opportunity for the students to compare the available data acquisition systems, extract their own conclusions of what fulfils the experimentation's requirements better and moreover keep the students up to date with all simple technological tools.

\section{ACKNOWLEDGMENTS}

All authors would like to express their gratitude to the PostGraduate Program of Studies "Automation of Productions and Services" of PUAS, for the financial support to undertake this research project

\section{REFERENCES}

[1] Georgopoulos A and Tsaliki E, (1993), Environmental Education: Principles- Philosophy, Methodology, Games and Exersices, Athens, Gutenberg Publishers

[2] Vlaxos G. and Kokotas P. (2000), The Role of Experimentation in Science and Teaching Learning Didactic Approaches in Physical Sciences: Modern Problems, Athens, Tipothito Publishers

[3] Coleman, E.B. \& Penuel, W.R. (2000). Web-Based Student Assessment for Program Evaluation. Journal of Science Education and Technology, 9(4), 327-342

[4] Ioannidou Irini, Tsitouridoy Melpomeni, Georgopoulos Alexandros, Psyxidou Rena, Kourakis Kostas, and Paraskevopoulos Stefanos (2010), Multimedia Technologies in Environmental Education: Research in Greek Area, Panhellenic Conference.

[5] Mavrikaki E. (2000). Environmental Education and New Technologies, Modern Education, 115, 21-31

[6] Moore, C. J. \& Huber, R. A. (2001). Support for EE from the National Science Education Standards and the Internet, The Journal of Environmental Education, 32(3), 21-25

[7] Papadimitriou B., (1998). Environmental Education and School, Athens, Tipothito Publishers

[8] Paraskeyopoulos S. and Korfiatis K. (2003), Environmental Education, Theory and Methodology, Christodoulidi Publishers

[9] Rickinson, M. (2001). Learners and Learning in Environmental Education: a critical review of the evidence, Environmental Education Research, Special Issue 7(3), 207- 320

[10] Rohwedder, P. (1999). Environmental Education goes High-Tech, Human Nature, (1)

[11] Skanavi and Sakelari M. (2002), The Evolution the Improvement and the Dynamics of Environmental Education, Athens, Gefires Publishers

[12] Trilianos $\mathrm{T}$ (2002), H Challenging a student to learn Athens

[13] Chalkidis A., Saridakis A and Tsakalis P, (1998), New Technology Applications in Environmental Education, http://www.epyna.gr/show/eisigisi5.doc

[14] Woolnough, B. and Allsop, T., (1985). Practical Work in Science, Cambridge, University Press. 